\title{
Un análisis del rol de las mujeres victimas del conflicto armado en Colombia en la constitución del derecho de reparación desde el pluralismo juridico y el enfoque de género ${ }^{1}$
}

\author{
An analysis of the role of women victims \\ of the armed conflict in Colombia in the \\ constitution of the right to reparation from \\ a legal pluralism and gender perspective
}

\author{
Gloria E. Zapata Serna iD
}

Universidad Pontificia Bolivariana, Colombia.

gloria.zapata@upb.edu.co

\begin{abstract}
Resumen
Las mujeres víctimas del conflicto armado colombiano han emprendido una lucha continua por ser reconocidas como víctimas del conflicto armado, organizándose y manifestándose públicamente. Su rol protagónico en esta lucha durante los últimos 25 años, que implica la concepción y puesta en marcha del derecho de reparación, se aborda desde una metodología cualitativa y documental, aplicada entre el 2017 y el 2019. Según lo constatado, el Estado colombiano reconoció el derecho de las víctimas a interponer recursos y obtener la reparación, pero sigue siendo muy poca la población reparada con respecto a la registrada. Se concluye que, a pesar de estos resultados, las mujeres siguen en pie de lucha por sus derechos como víctimas, convirtiéndose en permanentes promotoras de los derechos de todas las mujeres y logrando importantes aportes a la construcción del derecho de reparación, bajo una perspectiva pluralista del derecho.
\end{abstract}

Palabras clave: mujeres, víctimas, conflicto armado, derecho de reparación, pluralismo jurídico.

\begin{abstract}
Women victims of the Colombian armed conflict have undertaken a continuous struggle to be recognized as victims of the armed conflict, organizing themselves and demonstrating publicly. Their leading role in this struggle over the last 25 years, which involves the conception and implementation of the right to reparation, is addressed from a qualitative and documentary methodology, applied between 2017 and 2019. According to what was found, the Colombian State recognized the right of victims to file appeals and obtain reparation, but still very little of the population repaired with respect to the registered population. It is concluded that, despite these results, women continue to fight for their rights as victims, becoming permanent promoters of the rights of all women and achieving important contributions to the construction of the right to reparation, under a pluralistic perspective of law.
\end{abstract}

Keywords: women, victims, armed conflict, right to reparation, legal pluralism.

Articulo: Recibido el 30 de abril de 2021 y aprobado el 26 de junio de 2021

Cómo citar este artículo:

Zapata Serna, Gloria E. (2021). Un análisis del rol de las mujeres víctimas del conflicto armado en Colombia en la constitución del derecho de reparación desde el pluralismo jurídico y el enfoque de género. Reflexión política 23(48), pp. 56-68. doi: https://doi.org/10.29375/01240781.4139

1. Este texto surge de los análisis del capítulo $\mathrm{V}$ de la tesis de doctorado no publicada, titulada "La reparación de las víctimas del conflicto armado en Colombia con un enfoque de género", llevada a cabo en el Doctorado en Derecho de la Universidad de Quebec en Montreal (UQAM) y escrita por la Víctimas del Conflicto Armado en el marco de los Derechos Humanos 2017-2019" (Universidad Pontificia Bolivariana, Medellín, y Universidad Pablo de Olavide, Sevilla). 


\section{Introducción}

El 10 de junio de 2011 entra en vigencia en Colombia la Ley 1448 de 2011, más conocida como Ley de Víctimas y Restitución de Tierras. Una ley emblemática cuyo eje temático a considerar es el reconocimiento y consagración del derecho de las víctimas del conflicto armado interno colombiano a obtener la reparación. Llegar a este resultado normativo y a su puesta en marcha implicó un despliegue de acciones promotoras y concluyentes. En este sentido, este artículo reflexiona sobre cuál ha sido el rol de las mujeres víctimas y cómo ha incidido en una construcción pluralista del derecho de reparación en Colombia. Las mujeres víctimas del conflicto armado colombiano han logrado hacer del género no solo una herramienta analítica y crítica, sino también un instrumento de cambio social, a través de su movilización y su trabajo en las organizaciones que surgen como respuesta a las afectaciones sufridas en el marco del conflicto armado; estas fueron creadas para emprender una lucha por sus derechos, específicamente, por su derecho a la reparación. Sus importantes aportes a la configuración del derecho de reparación de las víctimas del conflicto, y a la puesta en marcha y control de este derecho, son referentes y soportes para una visión pluralista del derecho en el contexto colombiano.

El pluralismo jurídico es una perspectiva de análisis definida por muchos autores y que comprende diversas posiciones, pero que mantiene una idea en común: lo jurídico es más importante que la ley estática (Griffiths, 1986; Le Goff, 2012; MacDonald, 1996; Merry, 1988; Pospisil, 1967; B. de S. Santos, 1987; Tamanha, 2000). A partir de esta visión, se desarrollan las siguientes reflexiones en torno al reconocimiento del rol protagónico de las mujeres víctimas (como sociedad civil organizada) en la concepción, normalización y aplicación del derecho de reparación a las víctimas del conflicto armado colombiano. Además, se aborda el reconocimiento de sus propios sistemas normativos, muchos de los cuales se ubican al margen del ordenamiento estatal, con el fin de brindar atención y reparación a sus miembros en las organizaciones, quienes en la mayoría de los casos no las encuentran en las entidades del Estado.

A través de hechos concretos, recogidos en la investigación, se puede ver la materialización de esa construcción plural del derecho de reparación. Esta visión pluralista permite salirse del esquema clásico de las fuentes del derecho e identificar a las mujeres víctimas como intervinientes en la elaboración del derecho de reparación, distintas a las fuentes ya conocidas, es decir, el gobierno o los legisladores nacionales. Esa construcción pluralista le ha permitido al derecho colombiano avanzar y hacerlo con mayor efectividad, entendiendo por eficacia del derecho, en este contexto, "el grado en que los comportamientos sociales se ajustan a las normas de la ley” (Pomade, 2010, p. 112). Así, la visión metodológica pluralista permite distinguir entre políticas deseables y no deseables, en materia de atención y reparación, en donde las mujeres víctimas son las protagonistas de esta importante labor de validación.

Colombia es un país reconocido por su enorme riqueza natural. Igualmente, este país de 48.258.494 millones de habitantes (Departamento Administrativo Nacional de Estadística [DANE], s. f.), se reconoce también por tener uno de los conflictos armados internos más longevos del mundo. Un conflicto que, de acuerdo con el discurso del expresidente Juan Manuel Santos (2017) al momento de la firma del acuerdo, tuvo fin gracias al acuerdo de paz entre el gobierno nacional y la guerrilla más antigua del país, las FARC (Fuerzas Armadas Revolucionarias de Colombia). A partir de agosto de 2016, fecha de la suscripción del acuerdo, y desde el punto de vista de su alcance, Colombia es un país diferente. Es cierto que el país pudo avanzar en términos de paz, entre otras razones, porque públicamente ha reconocido su conflicto

armado y lo ha hecho parte de su memoria histórica. De igual manera, ha reconocido a sus víctimas y atendido causas estructurales del conflicto. Sin embargo, no es posible hablar de un posconflicto, sino de un posacuerdo, pues todavía existen otros grupos armados beligerantes en el territorio, como el Ejército de Liberación Nacional (ELN), el Clan del Golfo, los Rastrojos, los Pelusos y los Caparros, entre otros.

El Centro Nacional de Memoria Histórica de Colombia reconoce el carácter diverso y complejo del conflicto armado colombiano, tanto por sus actores como por sus múltiples causas (Centro Nacional 
de Memoria Histórica [CNMH], 2013). Lo identifica como un conflicto complejo, cuya resolución exige mayores esfuerzos. Según Camilo Azcarate (Garay Salamanca y Vargas Valencia, 2012), experto en resolución de conflictos y negociaciones, el conflicto colombiano no está asociado ni con la pobreza ni con el narcotráfico. Es de vieja data y su origen va más allá de la pobreza, el partidismo, la Guerra Fría y el narcotráfico. Para Azcarate, la esencia del conflicto radica en que diversos sectores de la sociedad colombiana han sido excluidos y sus necesidades básicas han sido desatendidas, llevándolos a utilizar métodos contraproducentes, incluso provenientes del mismo Estado, para hacerse escuchar y alcanzar sus objetivos, y haciendo de cada colombiano una víctima (Garay Salamanca y Vargas Valencia, 2012).

En palabras de Sánchez (1985), la violencia constituye "un elemento estructural del desarrollo político y social del país” (p. 25). Y, según Daniel Pécaut, el fenómeno de la violencia en Colombia se ha convertido en un modo de funcionamiento de la sociedad colombiana, y ha dado lugar a la aparición de diversas redes de influencia y regulación sobre la población, que ya no forman parte de un fenómeno ocasional o temporal, sino de una tendencia duradera en la sociedad (Pécaut, 1997, p. 4). Vista de esta manera, la violencia en Colombia se ha convertido en la herramienta principal de "aquellos sectores de la sociedad excluidos" (Butler, 2006, p. 14), cuyo uso e intensidad sirve como una manera de distinción entre unos y otros. En palabras de Judith Butler, "Hay formas de distribución de la vulnerabilidad, formas diferenciales de reparto que hacen que algunas poblaciones estén más expuestas que otras a una violencia arbitraria" (p. 14).

Esa violencia generalizada ha producido muchas pérdidas materiales y del medio ambiente, pero, sobre todo, muchas víctimas humanas directas e indirectas. Actualmente, según el Registro Único de Víctimas (RUV), Colombia tiene 9.123.123 víctimas, de las cuales 4.663.149 son hombres y 4.455.558 son mujeres (Unidad para la Atención y Reparación Integral a las Víctimas, 2021)². Por esta razón, las observaciones de la realidad social y la literatura al respecto dan cuenta de la difícil situación de las mujeres en medio del conflicto armado colombiano.
La experiencia de las mujeres en los conflictos es multifacética: "incluyen la detención, el aislamiento, la pérdida de seres queridos, la inseguridad económica y física, el incremento del riesgo de violencia sexual, las heridas de toda índole y hasta la muerte" (Ocvirk, 2004). Incluso antes de los hechos victimizantes, en sociedades que tienen estructuras con un marcado androcentrismo y donde se vive la cosificación de las mujeres, estas ya vivian experiencias de inequidades de género, como opresión y vulneración de sus derechos; y durante el conflicto, además de padecer las atrocidades propias de la violencia, han sido víctimas indirectas: "Se hacen cargo de sus niños, padecen el desplazamiento, son las responsables de conseguir recursos, y encima se quedan solas" (Ocvirk, 2004). Por lo tanto, el conflicto armado en Colombia no afecta de la misma manera a hombres y mujeres. De ahí la importancia que cobra la escucha activa de sus experiencias para que, a partir de allí, se conciban y pongan en marcha políticas públicas de atención y reparación acordes a sus necesidades.

Los datos secundarios y las reflexiones en el desarrollo del Doctorado en Derecho de la autora, Gloria Estella Zapata Serna, los cuales soportan estos análisis, permiten ubicar en dos grandes grupos a las mujeres víctimas en el contexto del conflicto armado en Colombia. El primero está conformado por mujeres víctimas individualmente consideradas, y el segundo, por mujeres víctimas agrupadas, organizadas y articuladas, que, para los efectos de estos análisis, se denominan sociedad civil organizada. Las mujeres del primer grupo se caracterizan por ser ciudadanas que se reconocen como víctimas del conflicto que ha vivido el país desde hace más de cinco décadas. También se caracterizan por declararse a la espera impaciente de una reparación -que consideran justa y necesaria - por todo lo sufrido en una guerra donde, según ellas, no tienen ninguna responsabilidad. Por el contrario, las mujeres del segundo grupo se caracterizan porque muchas de ellas prefieren llamarse sobrevivientes en lugar de víctimas. Para ellas, las mujeres han sufrido con mayor rigor las consecuencias del conflicto. Podría afirmarse que en Colombia la violencia toca a todos sus habitantes, pero de diferente manera; por eso, estas mujeres del segundo grupo reclaman ser escuchadas, que se les incluya en las decisiones y 
se les repare, teniendo en cuenta sus realidades y necesidades.

El presente texto analiza la labor de las mujeres víctimas del conflicto armado colombiano en la defensa y promoción de sus derechos, especificamente el derecho de reparación. También, se identifican acciones que hacen del entendimiento del derecho de reparación una construcción pluralista, permitiendo que el gobierno avance en la reparación de las víctimas de manera más efectiva. A continuación, se revisa la metodología y posteriormente, se examina el efecto de la voz de las mujeres en la concepción, puesta en marcha y control del derecho de reparación; y se presenta su propio sistema de reparación, que opera de manera paralela a la del gobierno colombiano. Finalmente, se hacen unas reflexiones a modo de conclusión.

\section{Metodologia}

Esta investigación fue abordada desde del método cualitativo, pues este apuntó:

a la comprensión de la realidad como resultado de un proceso histórico de construcción a partir de las lógicas de sus protagonistas, con una óptica interna y rescatando su diversidad y particularidad. Se hizo especial énfasis en la valoración de lo subjetivo, lo vivencial y la interacción entre los sujetos de la investigación. (Galeano Marín, 2004, p. 18)

A través de esta metodología, fue posible comprender lo vivido por las mujeres víctimas del conflicto armado colombiano y su lucha por el reconocimiento y materialización del derecho de reparación, lo cual se recrea en este artículo a través de sus pensamientos, creencias y sentimientos, expresados por medio de la palabra y en un contexto determinado. Así, fueron privilegiados como instrumentos de análisis, las reflexiones realizadas en el desarrollo de la tesis de Doctorado en Derecho aún no publicada de la autora, Gloria Estella Zapata Serna, y los datos secundarios de la investigación adelantada por las universidades Pablo de Olavide de Sevilla (España) y Pontificia Bolivariana de Medellín (Colombia) en el proyecto de investigación "Colombia: Reparación Integral de las Víctimas del Conflicto Armado en el marco de los Derechos Humanos 2017-2019”. Esta tuvo lugar en el departamento de Antioquia, con población específica de ocho municipios: Medellín, Barbosa,
Bello, Caldas, Copacabana, Envigado, Itagüí y Sabaneta (Iáñez-Domínguez y Pareja Amador, 2019; Universidad Pontificia Bolivariana et al., 2018).

Los datos secundarios se obtuvieron de 70 entrevistas a profundidad a mujeres víctimas de diferentes hechos victimizantes (desplazamiento forzado, homicidio, desaparición forzada, agresiones sexuales, tortura, extorsión, secuestro, despojo de tierras y minas antipersona), que se encontraban, como tal, registradas ante el gobierno colombiano. Asimismo, se hicieron diez entrevistas a líderes comunitarios, representantes de diversas ONG y personal de la administración pública; y se realizaron tres talleres de trabajo con mujeres líderes y víctimas, funcionarios públicos responsables de aplicar la Ley 1448 y representantes de organizaciones que trabajan por las víctimas. Las entrevistas y los talleres se lograron por intermedio de las unidades locales de atención y reparación a víctimas y algunas organizaciones de víctimas.

La población participante se encontraba domiciliada en el Área Metropolitana del Valle de Aburrá, entidad administrativa que agrupa diez municipios que coinciden en intereses comunes y que trabajan conjuntamente en pro del desarrollo económico, vial y social de sus comunidades. Al momento de la investigación, las mujeres víctimas y participantes contaban con edades variadas entre los 20 y más de 70 años. Sus hogares se encontraban conformados por uno, seis o más miembros, y eran víctimas, en su mayoría, por el desplazamiento y el homicidio.

Las entrevistas semidirigidas permitieron conocer las circunstancias de violaciones de los derechos humanos (época, lugar, hechos, bienes afectados, presuntos responsables), la vida de las víctimas antes de los hechos victimizantes, y su reconocimiento como víctimas por parte del gobierno colombiano, al igual que su proceso de atención y reparación. Por su parte, las entrevistas a líderes, funcionarios públicos y representantes de las ONG hicieron posible conocer su trabajo en favor de las víctimas, aciertos y desaciertos de la Ley 1448, y la lectura que ellos hacen de la realidad de las víctimas $\mathrm{y}$, específicamente, de las mujeres víctimas. Los datos obtenidos fueron analizados con la ayuda de la herramienta informática NVivo.

El análisis documental también fue un elemento importante en la obtención de los resultados; particularmente, el análisis de la Ley 1448 de 2011, desde una perspectiva política. 
Como expresa Sophie Daviaud (2010, p. 113), Colombia le rinde "veneración al derecho", pues para que un problema social logre alcanzar un interés político, este debe pasar primero por el radar jurídico. Así sucedió con la problemática de las víctimas en Colombia. Ellas lograron hacerse un poco visibles con la Ley 975 de 2005 (Congreso de la República de Colombia, 2005), conocida como Ley de Justicia y Paz, pues esta tenía como objetivo principal el desarme y la reincorporación a la vida civil de grupos al margen de la ley, pero las víctimas y su derecho a la reparación tuvieron un tratamiento más marginal, según Garay Salamanca y Vargas Valencia (2012), y las apreciaciones de los y las participantes del proyecto. Luego, con la promulgación de la Ley 1448 de 2011, las víctimas recobraron protagonismo y comenzó la época de la identificación, atención y reparación de las víctimas en todo el territorio nacional.

Antes de la existencia de estas normas había una indiferencia generalizada del gobierno y la sociedad colombiana ante el sufrimiento y las necesidades de las víctimas. Siendo prácticamente invisibles, la mayoría de las víctimas asumían su sufrimiento en silencio, se encontraban desarticuladas y desconocían su derecho a ser reparadas. La presencia de organizaciones internacionales, que antes se encontraban en otros países latinoamericanos que estaban viviendo dictaduras y procesos de transición, sirvió para la movilización de las víctimas, su empoderamiento y organización; y, quizás lo más importante, para que las víctimas se reconocieran, no como objetos de atención y asistencia, sino como sujetos de derecho, y tuvieran claro qué derechos les asistían como víctimas. Al respecto, resulta esclarecedor el capítulo de Daviaud sobre la representación de la violencia que se hicieron diversas organizaciones de derechos humanos basándose en el caso colombiano (Daviaud, 2010, pp. 219 y ss.).

A la fecha, Colombia cuenta con un marco normativo muy completo y ambicioso en materia de atención y reparación a víctimas. La norma marco tiene una vigencia de diez años, la cual terminó en junio de 2021, pero fue prorrogada por otros diez años más. En 2018, la Unidad de Atención y Reparación Integral a las Víctimas del conflicto armado en Colombia (UARIV) señaló: "Un total de 962.815 indemnizaciones con una inversión que supera los 5.9 billones de pesos" (Unidad para la Atención y Reparación Integral a las Víctimas,
2019). Hasta el momento, esto representaba, aproximadamente, tan solo el 10\% de la población reparada - específicamente en esta medida-. Durante las entrevistas realizadas, los dos años que faltaban para que se terminara la vigencia de la ley generaban una gran preocupación para las y los participantes. La mayoría de las participantes fueron víctimas que aún esperaban ser sujeto de alguna de las medidas de reparación contempladas en la ley (restitución, indemnización, rehabilitación, satisfacción y garantías de no repetición). En el momento de la investigación, Juan Fernando Cristo -quien fue el impulsor de la norma en su épocajunto con otros juristas gestionaron ante la Corte Constitucional la extensión de la vigencia, pues consideraban que aún no se le había cumplido a las víctimas del país (La Línea del Medio, 2019). En efecto, a través de la Ley 2078 de 2021 se aprobó la prórroga de la vigencia de la ley por otros diez años más, y de los Decretos ley y étnicos 4633, 4634 y 4635, todos de 2011.

\section{Resultados}

"El Premio Nobel se lo ganó por nosotras" (Entrevista a lider de ONG, julio 2017)

La representante de una organización de víctimas, a propósito del enfoque de género en la reparación, expresó: "aquí las víctimas son las mujeres" (entrevista a líder de ONG, julio 2017). Además de ser ellas las principales víctimas del conflicto armado en Colombia, son las que con sus voces, sin desfallecer, han alcanzado el reconocimiento de sus derechos; no solo como víctimas de un conflicto armado sino también como mujeres de la sociedad colombiana, que viven el conflicto de manera muy distinta a los hombres y reclaman ser escuchadas para que se conciba una atención y una reparación que sean más acordes a sus necesidades.

Por medio de su movilización y sus organizaciones, las mujeres víctimas han logrado generar una conversación con mayor sintonía entre la sociedad, el poder legislativo y el poder judicial, impidiendo la apropiación demagógica de las problemáticas y la discordancia entre normas y prácticas. Igualmente, han dado visibilidad local e internacional a su problemática, lo cual ha permitido sensibilizar a más personas sobre su situación de desprotección y vulnerabilidad. Aunque la tarea aún no está acabada, y pese a los obstáculos que en muchos casos representan amenazas 
permanentes para su vida y la de sus familiares, ellas continúan la labor, como heroínas nacionales y promotoras de los derechos humanos. Ellas saben que deben continuar trabajando, pues, como se ha demostrado en el curso de la investigación doctoral (cuyos análisis se amparan en los datos recogidos en el proyecto de investigación mencionado), el balance de la aplicación de la Ley 1448 es amargo: muchas mujeres víctimas aún no están reparadas integralmente. Asimismo, la situación del país en los últimos años muestra que el conflicto armado en Colombia está lejos de desaparecer y que cada día nace en el territorio una nueva víctima, a la que le asiste el derecho a la reparación.

Con base en el análisis de los datos secundarios, se identificaron acciones concretas que demuestran, en primer lugar, la implicación de las mujeres víctimas en el proceso decisional de creación de la norma, cuestionando el monopolio estático de dicha creación y aportando una nueva forma de establecer la validez de la norma jurídica; en segundo lugar, la participación en la concepción y elaboración del derecho de reparación; en tercer lugar, el control de aplicación del derecho de reparación, presionando constantemente para que este se aplique y, como ellas mismas lo expresan, "no se les olvide" (entrevista a líder de ONG, julio 2017); y, en cuarto lugar, la implementación de su propio sistema de reparación, en paralelo al establecido por el gobierno colombiano.

\subsection{Acciones en torno a la implicación de las mujeres victimas en el proceso decisional de creación y validación de la norma jurídica en materia de reparación}

Sentencia T-025 de 2004 de la Corte Constitucional de Colombia

Mediante esta sentencia se estableció que existe una violación masiva y reiterada de los derechos humanos de la población desplazada, y que las fallas estructurales de las políticas del Estado colombiano son un factor central que contribuye a dicha situación. A través de esta sentencia, fue posible que la población desplazada por el conflicto armado en Colombia lograra ser visibilizada (Rodríguez Garavito y Rodríguez Franco, 2010). Pero, ¿cómo nació esta sentencia y qué papel jugaron las víctimas del conflicto armado colombiano en su gestación? Hasta la fecha de la sentencia (Corte Constitucional de Colombia, 2004) y a pesar de la existencia de la Ley 387 de 1997, encaminada al restablecimiento de los derechos de las personas que habían sufrido el desplazamiento (Congreso de la República de Colombia, 1997), las víctimas del conflicto armado, específicamente los desarraigados, eran ignorados. Además, las autoridades tenían un desconocimiento absoluto del número de estas víctimas y la situación en que se encontraban. Esta indiferencia colectiva despertó en las víctimas - según los datos que aparecen en el Registro Único de Víctimas (RUV), casi la mitad son mujeres - la necesidad de movilizarse y actuar en búsqueda de la protección de sus derechos.

Tanto de forma individual, como también organizadas o representadas por organizaciones (Daviaud, 2010, pp. 291 y ss.), las familias desplazadas (conformadas, en su mayoría por madres cabeza de familia) instauraron numerosas acciones de tutela (consagrada en el artículo 86 de la Constitución Política de Colombia) en las cuales contaban su grave situación y la vulneración de sus derechos fundamentales (Iáñez-Domínguez, 2011). Lamentablemente, estos fallos de tutela fueron desatendidos por las entidades estatales. El reiterado incumplimiento de los fallos de tutela hizo que los desplazados siguieran interponiendo más acciones de tutela y de desacato, hasta que la Corte Constitucional decidió revisar los fallos de tutela y declarar el estado de cosas inconstitucional en materia de desplazamiento forzado en Colombia, a través de la Sentencia T-025 de 2004.

Esta sentencia y los autos de seguimiento que posteriormente ha emitido la Corte Constitucional permitieron implementar cambios importantes en el sistema jurídico colombiano, como la creación de la figura de carácter civil denominada Comisión de Seguimiento a la Política Pública del Desplazamiento Forzado, la cual ha posibilitado que el gobierno vaya superando esos estados inconstitucionales a medida que implementa las directivas de la Corte Constitucional. Igualmente, se incorporaron en la materia principios transversales, como el enfoque diferencial y el goce efectivo de los derechos, de los cuales se han apropiado las víctimas para reclamar una verdadera aplicación en sus territorios.

El enfoque diferencial propone a la diversidad como el punto de partida para la implementación de las políticas públicas. La apropiación de este enfoque en el contexto del conflicto armado colombiano, permite que personas históricamente discriminadas y de especial protección constitucional, puedan en términos de igualdad acceder a la reparación, dentro de las cuales se destacan las mujeres víctimas. 


\section{Los plantones de las víctimas}

En la presente investigación se entienden los plantones como las manifestaciones públicas de las víctimas, llevados a cabo en diferentes puntos del país. Una vez que las víctimas se instalan en lugares públicos, llevando la fotografia de sus familiares asesinados, desaparecidos o torturados -impresa en una camiseta o colgada en el pecho-, dan a conocer su dolor, la violación de sus derechos y sus reclamaciones al Estado colombiano, a través de consignas y pancartas. Entre algunas de las consignas utilizadas en los plantones, se resaltan las siguientes: "Los queremos vivos, libres y en paz" (Entrevista a líder de ONG, 2017), "Sin la voz de las mujeres la verdad no está completa” (Entrevista a líder de ONG, 2017), "Sin olvido", "Nunca más" (Entrevista a líder de ONG, 2017), "No es hora de callar" (Entrevista a líder de ONG, julio 2018).

Estas movilizaciones de víctimas han generado impactos de trascendencia nacional, por ejemplo, que la tan discutida definición de víctima fuera más inclusiva. En consecuencia, lograron que la noción ya consagrada en la Ley 975 de 2005 Ley de Justicia y Paz - no se incluyera de la misma forma en la posterior Ley 1448 de 2011, sino que en ella se tuviera en cuenta a otras víctimas, como aquellas que padecieron acciones de abuso de poder por parte de las fuerzas públicas y de otros actores armados, diferentes a la guerrilla o los paramilitares (Guglielmucci, 2017).

El impacto y resultado de los plantones de las mujeres víctimas del conflicto armado colombiano son destacados y exitosos. A través de este esfuerzo, las mujeres víctimas han logrado hacer avanzar el procesamiento de sus demandas en materia de reparación ante las autoridades electas democráticamente. Lograr insertarse en la agenda del gobierno llamando la atención de las autoridades como posibles asuntos de política pública, amerita el reconocimiento y la valoración.

\subsection{Acciones en torno a la participación de las victimas en la creación y elaboración del derecho de reparación}

Las mesas de víctimas

En el caso de la creación de la Ley 1448, los organismos de control en Colombia, en sus informes,

ya habían vislumbrado las fallas existentes en la participación real y efectiva de las víctimas en este nuevo propósito de atención y reparación que se proponía el gobierno colombiano. La falta de presencia activa de las víctimas fue considerada por los órganos de control como el estancamiento del establecimiento del enfoque diferencial consagrado por la misma ley y la inefectividad de un control fiscal. El control social de la política pública de atención y reparación integral de las víctimas del conflicto armado en Colombia es considerado vital para conseguir el goce efectivo de sus derechos (objetivo último de la ley) y, específicamente, la puesta en marcha del principio de enfoque de género, consagrado también en la ley (Contraloría General de la República et al., 2012).

Por lo anterior, muchas de las mujeres víctimas, a pesar de no creer en estos mecanismos de participación, insisten en asistir a las mesas municipales, departamentales y nacional de víctimas $^{3}$, con el ánimo de pronunciarse en contra de la inhumanidad y persistir en la lucha por sus derechos vulnerados; ya que, para ellas, "aquí no se ha reparado integralmente a nadie" (Entrevista a lider de ONG, julio 2017).

\section{Mesa de Conversaciones en La Habana}

Las negociaciones en La Habana (Cuba) entre el gobierno colombiano y la guerrilla Fuerzas Armadas Revolucionarias de Colombia (FARC-EP) debutaron en el año 2012 y culminaron con la firma de un Acuerdo General para la Terminación del Conflicto y la Construcción de una Paz Estable y Duradera, el 26 de agosto de 2016. Este acontecimiento se considera histórico, pues representó para la sociedad colombiana un acercamiento a la tan anhelada paz.

La participación de las víctimas del conflicto armado en la mesa de negociaciones significó un logro de la lucha de las organizaciones de víctimas, no solo en el ámbito nacional sino también internacional, ya que su accionar rompió con el esquema clásico de negociaciones en otras partes del mundo, donde se sentaban a la mesa únicamente los actores armados, dejando de lado a la sociedad civil y, sobre todo, a los directamente afectados por el conflicto, es decir, las víctimas ${ }^{4}$.

Las víctimas llevaron muchas propuestas a La Habana en el 2014, y no todas se cristalizaron. Sin embargo, en el caso particular de las mujeres

3. La reglamentación de las Mesas de Víctimas se encuentra en el artículo 14, armonizado con el artículo 29, 192 y 193 de la Ley 1448; el Decreto 3. reglamentario 4800 de 2011 y la Resolución 0388 de 2013 de la Unidad de Víctimas.

4. En palabras de Roddy Brett (2017, p. 35): "[i]a Cumbre de Mujeres y Paz, en octubre del 2013. Dicha cumbre fue histórica, dado que se reunieron aproximadamente 500 mujeres de 30 departamentos del pais, de 20 sectores sociales, con el apoyo de cinco países donantes de todo el sistema de las Naciones Unidas, con la aprobación del Gobierno y notificación a las FARC-EP. Dicha cumbre además gozo de una estrategia de medios de comunicacion. Las mujeres de la cumbre emitieron un comunicado a la mesa de conversaciones, leído públicamente, lo cual salió en todos los medios de comunicación". 
víctimas, a pesar de su escasa pero significativa participación, estas lograron avanzar en temas como la creación de la Subcomisión de Género, conformada para incluir solicitudes puntuales de las mujeres en varios puntos del Acuerdo. Esos momentos en La Habana representaron para las mujeres víctimas una gran oportunidad para hacerle comprender a los actores armados, al gobierno nacional y a la sociedad en general, que las mujeres han sufrido de manera desproporcionada las consecuencias del conflicto y que sus necesidades deben ser escuchadas y valoradas para lograr una adecuada reparación.

\subsection{Acciones de control de aplicación del derecho de reparación: encargo fiduciario a favor de niños y niñas victimas del conflicto armado}

Según los datos secundarios, de las cinco medidas que establece la ley (artículo 69), la indemnización puede denominarse como "la reina de las medidas": fue la medida de reparación con mayor mención y valoración por parte de las participantes en la investigación. Las mujeres víctimas consideraban que el dinero que les podían dar como compensación del daño causado era lo primero que deberían recibir, pues las condiciones en que quedaban después de los hechos victimizantes ponían en riesgo su dignidad y la de sus familias; por lo tanto, la indemnización representaba la única esperanza de estabilización para ellas. Lamentablemente, los resultados de la investigación demostraron que, si bien era la medida más esperada por las mujeres víctimas, también era la medida menos satisfecha.

Desde que el gobierno decidió reconocer y reparar a las víctimas del conflicto armado, el pago de una indemnización a las víctimas ha sido un tema de gran importancia. Al respecto existe gran cantidad de interrogantes y situaciones complejas que impiden el logro del objetivo de esta medida. Las mujeres víctimas, en sus organizaciones, son quienes mejor conocen sobre esta problemática $\mathrm{y}$, al ver las dificultades que se presentan en su ejecución, han impulsado cambios que pueden ser vistos como pequeños, pero que en la vida de las familias víctimas son muy significativos; por ejemplo, la creación del encargo fiduciario a favor de los niños y niñas víctimas del conflicto armado. Ellas manifiestan: "hicimos un derecho de petición al gobierno nacional, que metieran la plata que les correspondía a los hijos, a los niños, a una fiducia" (entrevista a líder de ONG, julio 2017).

Mediante estos ajustes a la medida de indemnización se logró garantizar el derecho de reparación de los niños y niñas víctimas del conflicto armado, pues su escasa edad e indefensión hacía que los adultos responsables, que recibían el dinero bajo el anterior procedimiento, dispusieran de él y, en algunas ocasiones, violentaran su derecho a la reparación. Al respecto, expresaron:

Nosotras las abuelas estábamos cometiendo como un atropello contra los nietos. Les daban la reparación a las abuelas y entonces venían y llamaban a los hijos "Hijo, ¿usted qué quiere? Me dieron la reparación de su hermana. ¿Qué quiere? Usted, la moto..." Pero no compartían la reparación con los niños, con los nietos. (Entrevista a líder de ONG, julio 2017)

\subsection{La puesta en marcha de sistemas normativos en materia de reparación, en paralelo al ordenamiento estatal}

Las acciones que se mencionan a continuación, dan cuenta de ese arduo trabajo de las organizaciones de víctimas por llenar los vacíos del Estado y la institucionalidad en materia de atención y reparación, incluso para corregir errores en la concepción y materialización de la normatividad que regula tales asuntos. La actualidad jurídica, cada vez nos muestra que no existe un único sistema normativo para un espacio determinado, sino que siempre han existido varios, solo que pocas veces se hacen visibles. En esta ocasión, se pretende reconocer esa institucionalidad creada por las mujeres víctimas del conflicto armado colombiano debidamente organizadas, que coexisten con las propias del Estado en procura de una respuesta más efectiva al clamor de las víctimas.

\section{Caracterizar bien y mejor a las víctimas}

"Entonces hicimos una caracterización, dentro de la organización, de quién tenía vivienda, quién no. Quién tenía estudios. Eso nos dio para poder movernos en el mismo país. Es decir, el hecho que fuera, teníamos esa caracterización" (Entrevista a líder de ONG, julio 2017). Una de las grandes preocupaciones de las organizaciones es conocer bien quiénes son sus miembros y cuáles son sus verdaderas necesidades, para así emprender 
acciones más eficaces. Con respecto a esta tarea, según los funcionarios que operan el sistema de reparación, la caracterización ha sido una tarea inconclusa. Quienes realizan esta labor generalmente trabajan por contratos, los cuales son de corta duración. Esto implica que, al terminarse el contrato, se requiere otro funcionario, y, al llegar un nuevo funcionario, muchas veces sin la experiencia del anterior, es necesario comenzar desde cero. Esta situación representa un completo retroceso para el trámite. En palabras más simples, según los y las participantes, siempre es un reproceso y una revictimización. Una funcionaria que se desempeña en este tipo de labores expresó:

Es un proceso de 4 meses, una fase de 4 meses de trabajo, tú terminas ese proceso de 4 meses, se termina tu contrato, yo no voy a ser yo misma la que voy a seguir en esa atención con esa población o con esa víctima, sino que vienen otras promotoras, otros profesionales diferentes... y claro, no conocen del contexto, el conflicto de ese territorio, no conocen la población, no conocen cada víctima... Entonces, ¿qué van a hacer? Otra vez a caracterizar, entonces para mí eso es revictimizar, o sea no estamos haciendo un verdadero proceso psicosocial de avance sino de retroceso. (Taller Organizaciones Civiles, agosto 2017)

\section{Trabajar con el subregistro}

El Registro Único de Víctimas (RUV) fue creado a través de la Ley 1448 de 2011 (artículo 154), con el fin de identificar el universo de víctimas del conflicto armado en Colombia. Por su parte, las organizaciones de víctimas atienden a las víctimas independientemente de que estén o no reconocidas como tal por el gobierno nacional. Así, como las víctimas que no aparecen en el sistema de Registro Único que controla el gobierno colombiano no pueden recibir ningún tipo de atención, ni ninguna medida de reparación, lo que le ofrecen al respecto las organizaciones será la única ayuda que reciban. En este sentido, las organizaciones de víctimas representan, en sus vidas, la presencia de un Estado completamente inexistente para ellas.

\section{Formar y capacitar a las víctimas}

Durante las entrevistas, las participantes expresaron reiteradamente la importancia de la educación para ellas y sus familias, especialmente, para los jóvenes. Igualmente, señalaron las fallas que presenta la oferta del Estado; se refirieron a la inexistencia de programas acordes a su condición, y a la imposibilidad de acceder al estudio por no lograr conciliar las necesidades, las demandas y los tiempos de los ámbitos de estudio con los familiares. Con respecto a sus hijos, señalaron la falta de oportunidades para ingresar a la universidad. Frente a esta situación, las organizaciones de víctimas responden con una gestión permanente en la consecución de capacitaciones y becas para atender esta necesidad de una forma más adaptada a sus realidades. Al igual que las víctimas, las organizaciones valoran mucho la educación y encuentran en ella posibles salidas al estado de vulnerabilidad que viven las víctimas y los demás miembros de sus familias:

Entonces para mí la educación es fundamental. Si no estudias, ¿para qué...?, ¿para qué vives? Porque eres un ente que vas a engordar. ¿Qué piensa una persona que no estudia, que no lee, que no escucha? Es un ente. $Y$ aquí ya vino gente así. Es que yo en mi finca salía a coger café, regresaba a las 9, por la tragadera del desayuno de la gente. Regresaba otra vez, seguía cogiendo café. Al almuerzo... la hija pesaba 129 kilos... porque había... haciendo de comer iba comiendo a poquito... mire, la educación es fundamental. Si este país no se educa para la paz, aquí no hay paz. Y empezamos por las víctimas y tenemos que seguir con los victimarios [...] Si las víctimas se educan, es otro precio, no les da miedo hablar, no les da miedo reclamar. Y los derechos humanos, ahí van encajados, porque si tú te educas, ya vas hablando con el otro y el otro y ya le vas contando las peripecias de ella, y se van formando grupos de educadores. (Entrevista a líder de ONG, julio 2017)

\section{Búsqueda de la verdad}

La verdad, para quienes perdieron sus seres queridos o para los que aún están desaparecidos, representa una de las mejores maneras de ser reparadas. Comprender y respetar este sentir de las mujeres víctimas ha sido esencial para la movilización de las organizaciones.

La idea de nosotros era buscar los desaparecidos en el país. Eso era todo lo que nosotros hacíamos. Salíamos seis, siete mujeres a buscar a los desaparecidos, en cualquier sitio donde nos decían que había personas enterradas allá íbamos a ver si estaban los de nosotros [...] Para eso se formó este movimiento. Primero para buscar la verdad, el 
respeto de los derechos de las víctimas mujeres, de esas mujeres campesinas [...] Mire, ellas esperan de la reparación, el saber de sus hijos, saber la verdad. Mire, cuando a una mujer le dicen "mire, que su hijo está en tal parte, para que lo lleven a los fiscales y saque a su hijo para que le hagan la exhumación". Las madres se arrodillan... “igracias, Señor!”, se arrodillan ante Dios y dicen "Señor, gracias"... Por lo menos supieron la verdad. (Entrevista a líder de ONG, julio 2017)

Para conseguir esa verdad tan anhelada han debido emprender muchas acciones sin la ayuda de nadie, solo con el ánimo de dar reparación a estas familias: "Nosotros la verdad la conseguimos por nuestros propios medios" (entrevista a líder de ONG, julio 2017). En ese orden de ideas, ellas establecieron contacto con los actores armados:

nosotros hemos hecho acercamientos a las cárceles, porque tenemos que interlocutar los actores armados para que ellos también trabajen la reconciliación con nosotros [...] del acercamiento con los paramilitares sacamos 75 verdades, que nos decían "vayan donde tal parte...donde busque ese campesino que sabe dónde está el hijo de tal..." y arrancamos para allá. (Entrevista a líder de ONG, julio 2017).

Recorrían los municipios y barrios de la ciudad en búsqueda de sus familiares: "nosotras nos dedicábamos a sacar esos cadáveres y llevarlos a la morgue [...] yo tengo que investigar, ahí puede estar mi hijo, los hijos de mi compañera, los de la Comuna 1, 13..." (entrevista a líder de ONG, julio 2017).

Sensibilizar a las autoridades frente al trato a y la inclusión de las víctimas

El reconocimiento de las víctimas, de su estado de vulnerabilidad y vulneración, y la puesta en marcha de acciones concretas para brindarles atención y reparación, ha sido un proceso largo y lento en el país. Los colombianos que tuvieron que desplazarse por el conflicto y llegar a las grandes ciudades a buscar refugio, sintieron el rechazo de la sociedad, el menosprecio de la gente, y la indiferencia y el malestar de las autoridades para asumir sus responsabilidades y compromisos establecidos en la ley. Pero gracias al trabajo de las organizaciones, se pudo cambiar un poco el panorama, concientizar, y dejar consignas de trabajo claras y contundentes, como una perspectiva basada en la noción "primero el ser humano":

tuvimos que sensibilizar a los alcaldes de este país, porque los malos tratos contra las víctimas eran... "vieja mugrosa, vieja loca”... De todo las trataban, tuvimos que sensibilizar: "a usted le aumentaron el sueldo, ¿sabe por qué?, para que atendiera bien a las víctimas", a los personeros. A los personeros de aquí...le cuento una cosa, así se va a llamar la personería: primero el ser humano, venga descalzo, sucio o loco, venga como sea, primero el ser humano. Y si nosotros no irradiamos eso a las comunidades, siguen tratando mal. A nosotras nos tratan mal cada rato, cuando empezamos en la Casa de la Memoria a hablar de reconciliación [...] creo que en el tema psicosocial le falta mucho, mucho al Estado colombiano, de centrarse en la necesidad de la población víctima, pero realmente qué es lo que necesita, y que sea un proceso que verdaderamente lo logre sacar de ese daño tanto mental como psicológico que quedó [para] cada persona, por qué es importante la rehabilitación de cada individuo, no de mirar una caracterización de una población para decir "me gasté tanto dinero", "esto fue tanto", "ya no hay recurso", "no podemos seguir"... porque entonces vamos a seguir revictimizando y vamos a quedar peor de lo que estábamos en vez de haber sacado todo ese dolor y todo eso que nos negó la ley. (Entrevista a líder de ONG, julio 2017)

\section{Empoderamiento de las mujeres. Ejercicio pleno de la ciudadanía ${ }^{5}$}

Las organizaciones han identificado un grave problema con las víctimas del conflicto armado: ellas no quieren que se les siga viendo como objetos de asistencia y de ayuda humanitaria, o como beneficiarias pasivas de programas de protección sociales. Lo que ellas quieren es, sin duda, que se les considere y trate como lo que son, sujetos de derechos y obligaciones, en una sociedad que vive un conflicto y que quiere la paz. Por eso, desean tener una verdadera inclusión política. En sus palabras se expresa la postura contradictoria del gobierno frente a las víctimas:

5. En este análisis, se entiende la ciudadanía "en el marco de una perspectiva que toma la ciudadanía de manera dinámica como un proceso en construcción" (traducción propia a partir de Jenson, 2013, p. 115). 
primero lo convirtieron en pedidor; en pedidor, únicamente venga, le doy un subsidio, un subsidio, un subsidio... y luego le dicen usted salga de ser víctima y conviértase en ciudadano [...] es muy contradictorio, muy contradictorio, de manera muy clara, el Estado quiere tener a un mundo de gente, de víctimas, simplemente para darle un subsidio, pero no se meta a reclamar otros derechos. (Taller con Organizaciones Civiles, agosto 2017)

En ese orden de ideas, las mujeres víctimas luchan por que las demás mujeres en esta situación se preparen y ejerzan con consciencia sus derechos como ciudadanas, por eso acuden a las universidades y a otras ONG para obtener formación en esta temática específicamente:

creo que es muy importante que muchas mujeres empiecen a capacitarse y a formarse como sujetos políticos, a conocer más de las leyes para poder exigir sus derechos porque va a ser la única forma de que sea algo reparado. (Taller con Organizaciones Civiles, agosto 2017)

A través de estas acciones concretas que se acaban de reseñar, las mujeres víctimas del conflicto armado organizadas, materializan la visión pluralista del derecho de reparación. El trabajo desplegado por las organizaciones demuestra que tienen normas, que sus normas contienen la amenaza de sanciones, cuentan con sujetos que están ahí para decir qué se debe de hacer y cómo se debe hacer. Igualmente, sus miembros saben cuáles normas hacen parte del sistema y que deben obedecerse, además de cuáles son los mecanismos que están dispuestos para resolver las posibles diferencias. De esta manera, estas organizaciones de mujeres engrandecen ese cuerpo normativo que, en materia de reparación de víctimas del conflicto armado, tiene la sociedad colombiana.

\section{Conclusiones}

Los análisis desarrollados permitieron resaltar el rol protagónico de las mujeres víctimas, reconocidas como sociedad civil organizada, en la promoción y defensa de sus derechos; específicamente, en la construcción del derecho de reparación en el sistema jurídico colombiano. Por tanto, se les reconoce a las mujeres víctimas del conflicto armado colombiano su gran aporte al cambio social. En épocas de conflicto y violencia, y también de implementación del acuerdo de paz, la intervención de las mujeres víctimas del conflicto colombiano, se tradujo en lograr que en esta sociedad no se reduzca a la mujer víctima a un simple objeto de atención, protección y caridad; y se revierta esta noción, para considerarla como una mujer empoderada en todos los dominios de la vida, participativa de las decisiones de la vida pública y privada, y promotora de la paz y la reconciliación.

$\mathrm{Al}$ retomar la idea común de la perspectiva pluralista del derecho, lo jurídico es mucho más que ley estatal, se destacó cómo el trabajo de las mujeres víctimas lleva a cuestionar la concepción dogmática del derecho y demuestra la existencia, dentro de una misma sociedad, de muchos sistemas legales que interactúan entre ellos, como es el caso del sistema de reparación propio de las organizaciones de mujeres víctimas. Un sistema que responde a necesidades puntuales de las víctimas, que han sido relegadas a un segundo plano en la agenda del gobierno nacional.

A través de estos análisis queda claro que la meta de reparación integral de las víctimas del conflicto armado interno reconocidas por el Estado no se ha alcanzado aún, pues faltan millones de mujeres víctimas por ser reparadas y, sobre todo, por alcanzar ese empoderamiento que les permita reconocerse como sujetos de derecho y actuar de conformidad con tal situación. Por ello, es necesario trabajar en pro de las organizaciones de mujeres víctimas, apoyarlas y acompañarlas en ese crecimiento colectivo; ya que, como manifestaron varias mujeres entrevistadas, a ellas les encantaría poder participar en esas asociaciones, porque serían muchos los beneficios que conseguirían, pero sus quehaceres y sus necesidades básicas insatisfechas les impiden implicarse allí.

Estas organizaciones, como lo han venido haciendo, contribuyen a otorgar con eficacia las medidas de reparación consagradas en la Ley 1448 y a descentralizar muchas de las acciones que materializan la reparación tal como fue concebida por dicha ley. Asimismo, recrean como mayor asertividad lo que debe contener la reparación de las mujeres víctimas del conflicto armado colombiano, ya que a través de su intervención, movilización y organización, adquieren mayor entendimiento de lo que verdaderamente representa para una mujer víctima en Colombia la reparación. 


\section{Referencias}

Brett, R. (2017). La voz de las víctimas en la negociación: sistematización de una experiencia. Programa de las Naciones Unidas para el Desarrollo [PNUD].

Butler, J. (2006). Vida precaria. El poder del duelo y la violencia. Paidós.

Centro Nacional de Memoria Histórica [CNMH]. (2013). ¡Basta ya! Colombia: memorias de guerra y dignidad. Centro Nacional de Memoria Histórica $[\mathrm{CNMH}]$. http://www.centrodememoriahistorica. gov.co/micrositios/informeGeneral/descargas.html

Congreso de la República de Colombia. (1997). Ley 387. Por la cual se adoptan medidas para la prevención del desplazamiento forzado; la atención, protección, consolidación y estabilización socioeconómica de los desplazados internos por la violencia en la República de Colombia. Diario Oficial No. 43.091. http://www.secretariasenado.gov. co/senado/basedoc/ley_0387_1997.html

Congreso de la República de Colombia. (2005). Ley 975. Por la cual se dictan disposiciones para la reincorporación de miembros de grupos armados organizados al margen de la ley, que contribuyan de manera efectiva a la consecución de la paz nacional y se dictan otras disposiciones para acuerdos humanitarios. Diario Oficial No. 45.980. http://www.secretariasenado.gov.co/senado/basedoc/ ley_0975_2005.html

Congreso de la República de Colombia. (2011). Ley 1448. Por la cual se dictan medidas de atención, asistencia y reparación integral a las víctimas del conflicto armado interno y se dictan otras disposiciones. Diario Oficial No. 48.096. http://www. secretariasenado.gov.co/senado/basedoc/ley_1448_2011. html

Corte Constitucional de Colombia. (2004, enero 22). Sentencia T-025/04 (Manuel José Cepeda Espinosa, M. P.). https://www.corteconstitucional.gov.co/ relatoria/2004/t-025-04.htm

Contraloría General de la República, Procuraduría General de la Nación y Defensoría del Pueblo. (2012). Primer Informe de seguimiento y monitoreo de los órganos de control a la Ley 1448 de 2011 de Victimas y Restitución de Tierras. https:// viva.org.co/attachments/article/195/INFORME_MONITOREO_Y_SEGUIMIENTO_LEY_1448_2011.pdf

Daviaud, S. (2010). L'enjeu de droits de l'homme dans le conflit colombien. Karthala.

Departamento Administrativo Nacional de Estadística [DANE]. (s. f.). ¿Cuántos somos? https://www. dane.gov.co/index.php/estadisticas-por-tema/demografia-y-poblacion/censo-nacional-de-poblacion-y-vivenda-2018/cuantos-somos
Galeano Marín, M. E. (2004). Diseño de proyectos de la investigación cualitativa. Fondo Editorial Universidad EAFIT.

Garay Salamanca, L. J., y Vargas Valencia, F. (2012). Memoria y Reparación: Elementos para una justicia transicional pro víctima. Universidad Externado de Colombia.

Griffiths, J. (1986). What is Legal Pluralism? The Journal of Legal Pluralism and Unofficial Law, 18(24), 1-55. https://doi.org/10.1080/07329113.1986.10756387

Guglielmucci, A. (2017). El concepto de víctima en el campo de los derechos humanos: una reflexión crítica a partir de su aplicación en Argentina y Colombia. Revista de Estudios Sociales, 59, 83-97. http://journals.openedition.org/revestudsoc/608. https:// doi.org/10.7440/res59.2017.07

Iáñez-Domínguez, A. (2011). Mujeres y desplazamiento forzado. Estrategias de vida de jefas de hogar en Medellín. Aconcagua Libros.

Iáñez-Domínguez, A., y Pareja Amador, A. J. (2019). Mujeres y violencia en Colombia. La reparación a las víctimas del conflicto armado. Catarata.

Infobae. (2021, abril 5). Indepaz alerta por el aumento de desplazamientos masivos en lo que va de 2021. Infobae. https://www.infobae.com/america/colombia/2021/04/05/indepaz-alerta-por-el-aumento-dedesplazamientos-masivos-en-lo-que-va-de-2021/

Jenson, J. (2013). Quand les politiques sociales s'intéressent au care: Conséquences pour femmes et le régime de citoyenneté. En D. Paternotte \& N. Nagels (Eds.), Imaginer la citoyenneté. Hommage à Bérengère Marques-Pereira. Louvain-laNeuve: Academia L'Harmattan

La Línea del Medio. (2019, marzo 26). Demanda pide prorrogar vigencia de Ley de Víctimas. La Línea del Medio. https://lalineadelmedio.com/demanda-pide-prorrogar-vigencia-de-ley-de-victimas/

Le Goff, J. (2012). Georges Gurvitch. Le pluralisme créateur. Michalon. https://doi.org/10.3917/micha.legof.2012.01

MacDonald, R. A. (1996). Les Vieilles Gardes. Hypothèses sur l'émergence des normes, l'internormativité et le désordre à travers une typologie des institutions normatives. En J.-G. Belley (Ed.), Le droit soluble: contributions québécoises à l'étude de l'internormativité. LGDJ.

Merry, S. E. (1988). Legal Pluralism. Law \& Society Review, 22(5), 869-896. https://doi.org/10.2307/3053638

Ministerio de Ambiente y Desarrollo Sostenible [Minambiente]. (2019, mayo 21). Colombia, el segundo país más biodiverso del mundo, celebra el Día Mundial de la Biodiversidad. https://www.minambiente.gov.co/index.php/noticias-minambiente/4317-colombia-el-segundo-pais-mas-biodiverso-del-mundo-celebra-el-dia-mundial-de-la-biodiversidad

Ocvirk, V. (2004, marzo 5). Mujeres y conflictos armados: una lucha en todos los frentes. Comité Inter- 
nacional de la Cruz Roja [CICR]. https://www.icrc. org/es/doc/resources/documents/misc/mujeresyconflictosocvirk.htm

Pécaut, D. (1997). Presente, pasado y futuro de la violencia. Análisis politico, 30, 3-36. https://revistas.unal. edu.co/index.php/anpol/article/view/76353. https://doi. org/10.2307/3467131

Pomade, A. (2010). Les implications de l'influence normative de la Société Civile en droit de l'environnement sur les théories des sources du droit et de la validité. Revue interdisciplinaire d'études juridiques, 64(1), 87-122. https://doi.org/10.3917/ riej.064.0087

Pospisil, L. (1967). Legal levels and multiplicity of legal systems in human societies. Journal of Conflict Resolution, 11(1), 2-26. https://doi. org $/ 10.1177 / 002200276701100102$

Rodríguez Garavito, C., y Rodríguez Franco, D. (2010). Cortes y cambio social. Cómo la Corte Constitucional transformó el desplazamiento forzado en Colombia. Centro de Estudios de Derecho, Justicia y Sociedad, Dejusticia. https://www.dejusticia.org/wp-content/uploads/2017/04/fi_name_recurso_185.pdf

Sánchez, G. (1985). La violencia y sus efectos en el sistema político colombiano. En A. Díaz U. (Ed.), Once Ensayos sobre la Violencia en Colombia (pp. 209-258). Fondo Editorial CERAC y Centro Gaitán.

Santos, B. de S. (1987). Law: A Map of Misreading. Toward a Postmodern Conception of Law. Journal of Law and Society, 14(3), 279-302. https://doi. org/10.2307/1410186

Santos, J. M. (2017, noviembre 24). Palabras del Presidente Juan Manuel Santos con motivo del primer aniversario de la firma del Acuerdo de Paz en el Teatro Colón. Presidencia de la República de Colombia. http://es.presidencia.gov.co/ discursos/171124-Palabras-del-Presidente-Juan-ManuelSantos-con-motivo-del-primer-aniversario-de-la-firmadel-Acuerdo-de-Paz-en-el-Teatro-Colon

Tamanha, B. Z. (2000). A Non Essentialist Version of Legal Pluralism. Journal of Law and Society, 27(2), 296-321. https://doi.org/10.1111/1467-6478.00155

Unidad para la Atención y Reparación Integral a las Víctimas. (2019, enero 15). Unidad para las Victimas alcanzó en 2018 cifra histórica de indemnizaciones a sobrevivientes del conflicto armado. Unidad para la atención y reparación integral a las victimas. https://www.unidadvictimas. gov.co/es/reparacion/unidad-para-las-victimas-alcanzo-en-2018-cifra-historica-de-indemnizaciones\#: :tex$\underline{\mathrm{t}=\mathrm{Un}}$ total de 962.815 indemnizaciones,a sobrevivientes del conflicto armado.

Unidad para la Atención y Reparación Integral a las Víctimas. (2021, marzo 31). Víctimas conflicto armado. Unidad para la atención y reparación integral a las victimas. https://www.unidadvictimas. gov.co/es/registro-unico-de-victimas-ruv/37394

Universidad Pontificia Bolivariana, Universidad Pablo de Olavide y Agencia Andaluza de Cooperación Internacional para el Desarrollo. (2018). Reparación integral de las mujeres víctimas del conflicto armado. Medellín, Museo Casa de la Memoria. 